\title{
High-dose dexamethasone treatment for COVID-19 severe acute respiratory distress syndrome: a retrospective study
}

\author{
Alessandra Vecchié ${ }^{\text {- Alberto Batticciotto }}{ }^{1}$ - Flavio Tangianu ${ }^{1}$ - Aldo Bonaventura ${ }^{1}$ (D) Benedetta Pennella ${ }^{1}$. \\ Alessia Abenante $^{1} \cdot$ Rossana Corso $^{1} \cdot$ Stefano Grazioli $^{1} \cdot$ Nicola Mumoli $^{2} \cdot$ Ombretta Para $^{3} \cdot$ Andrea Maria Maresca $^{4}$. \\ Daniela Dalla Gasperina ${ }^{4}$. Francesco Dentali ${ }^{4}$
}

Received: 28 January 2021 / Accepted: 27 June 2021 / Published online: 17 July 2021

(c) Società Italiana di Medicina Interna (SIMI) 2021

\begin{abstract}
Low-dose dexamethasone reduces mortality in patients with coronavirus disease 2019 (COVID-19)-related acute respiratory distress syndrome (ARDS). We retrospectively analyzed the efficacy of high-dose dexamethasone in patients with COVID19-related ARDS and evaluated factors affecting the composite outcome (death or invasive mechanical ventilation). From March 4th to April 1st 2020, 98 patients with COVID-19 pneumonia were included. Those who after at least 7 days from symptom onset presented a worsening of the respiratory function or of inflammatory biomarkers were started on intravenous high-dose dexamethasone ( $20 \mathrm{mg}$ daily for 5 days, followed by $10 \mathrm{mg}$ daily for 5 days). Most patients were males (62\%) with a mean age of 69 years. Hypertension and cardiovascular disease (CVD) were prevalent. Following dexamethasone treatment, a significant improvement in $\mathrm{PaO}_{2} / \mathrm{FiO}_{2}$ (277.41 [178.5-374.8] mmHg vs. 146.75 [93.62-231.16] mmHg, $p<0.001$ ), $\mathrm{PaO}_{2}$ (88.15 [76.62-112.0] mmHg vs. 65.65 [57.07-81.22] mmHg, $p<0.001$ ), and $\mathrm{SpO}_{2}$ (96 [95-98]\% vs. 94 [90-96]\% , $p<0.001)$ was observed. A concomitant decrease in C-reactive protein and ferritin levels was found (132.25 [82.27-186.5] $\mathrm{mg} / \mathrm{L}$ vs. 7.3 [3.3-24.2] mg/L and 1169 [665-2056] ng/mL vs. 874.0 [569.5-1434] ng/mL, respectively; $p<0.001$ for both vs. baseline). CVD was found to increase the risk of the composite outcome (RR 7.64, 95\% CI 1.24-47.06, $p=0.028$ ). In hospitalized patients with COVID-19-related ARDS, high-dose dexamethasone rapidly improves the clinical status and decreases inflammatory biomarkers. CVD was found to increase the risk of the composite outcome. These data support the importance of randomized clinical trials with high-dose dexamethasone in COVID-19 patients.
\end{abstract}

Keywords COVID-19 $\cdot$ SARS-CoV-2 $\cdot$ ARDS $\cdot$ Dexamethasone $\cdot$ Inflammation $\cdot \mathrm{PaO}_{2} \cdot \mathrm{FiO}_{2}$

\section{Introduction}

Alessandra Vecchié and Alberto Batticciotto equally contributed as first authors to this work.

Francesco Dentali

francesco.dentali@asst-settelaghi.it

1 Department of Internal Medicine, ASST Sette Laghi, Varese, Italy

2 Department of Internal Medicine, Ospedale di Magenta, ASST Ovest Milanese, Legnano, Italy

3 SOD Medicina Interna I, Azienda Ospedaliero-Universitaria Careggi, Firenze, Italy

4 Department of Medicine and Surgery, Insubria University, Varese, Italy
Severe acute respiratory syndrome coronavirus 2 (SARS$\mathrm{CoV}-2)$ is responsible for the pandemic of coronavirus disease 2019 (COVID-19) [1]. Although most patients experience mild symptoms, a small proportion of them develops severe, viral interstitial pneumonia with increasing hypoxia that can cause acute respiratory distress syndrome (ARDS), multiorgan failure, and death [2-5].

McGonagle et al. [6] hypothesized that, in the first stages, the virus induces a temporary immunodeficiency status (i.e., interferon suppression and lymphopenia) [7]. The second step consists in the activation of anti-viral mechanisms, that may trigger an exaggerated immune response characterized by a cytokine storm, i.e. high levels of interleukin (IL)-6 [8] and other cytokines like IL-1, tumor necrosis factor (TNF)- $\alpha$, IL-18, and granulocyte-macrophage 
colony-stimulating factor (GM-CSF) [2, 9-11]. All these events may then culminate and/or sustain immunothrombosis, that is responsible for poor outcomes [12].

Numerous collaborative trials investigated the effectiveness of remdesivir and some immunomodulating agents with contrasting or neutral results [13-18]. The Randomised Evaluation of COVID-19 Therapy (RECOVERY) trial has investigated the role of low-dose dexamethasone ( $6 \mathrm{mg}$ daily up to 10 days) on top of usual care vs. usual care alone in patients with SARS-CoV-2 infection [19]. A reduced 28-day mortality was found in the dexamethasone group compared with the usual care group, with the largest benefit among those patients receiving invasive mechanical ventilation or any oxygen support at the time of randomization. Few weeks before the outbreak of COVID-19 pandemic, a multicenter Spanish study demonstrated that early administration of high-dose dexamethasone in patients with established moderate-to-severe ARDS reduced the duration of mechanical ventilation and overall mortality [20].

The aim of our work was to retrospectively review the efficacy of high-dose dexamethasone in patients with SARSCoV-2 pneumonia-related ARDS admitted to a COVID-19 hub in Lombardy (Italy) during the first wave of the disease.

\section{Materials and methods}

\section{Design}

From March 4th to April 1st, 2020, all adult patients ( $\geq 18$ years) with confirmed COVID-19 pneumonia (laboratory real-time-polymerase chain reaction [RT-PCR] SARSCoV-2 positivity and/or chest computed tomography [CT] scan suggestive for interstitial pneumonia) admitted to the High-Intensity Care of the Internal Medicine Department (Ospedale di Circolo - Fondazione Macchi, ASST dei Sette Laghi, Varese, Italy) were included in the present retrospective study. Patients were admitted to our High-Intensity Unit if they (i) tested positive for severe SARS-CoV-2 infection or had confirmed pneumonia on chest X-ray or highly suspected findings for COVID-19 on chest CT scan; (ii) had respiratory failure requiring oxygen administration and (iii) did not require intubation according to anesthesiologist evaluation. Based on low-evidence guidelines available during the first weeks of the pandemic, they were treated with lopinavir/ ritonavir, hydroxychloroquine, low-molecular weight heparin (LMWH), oxygen and, in case of a suspected bacterial superinfection, antibiotic therapy (e.g., azithromycin, ceftriaxone or levofloxacin). After at least 7 days from symptom onset, those who presented a worsening of the respiratory function, increasing value of C-reactive protein (CRP) compared with baseline, and an arterial oxygen partial pressure to fractional inspired oxygen ratio $\left(\mathrm{PaO}_{2} / \mathrm{FiO}_{2}\right)<300 \mathrm{mmHg}$ were treated with intravenous dexamethasone $(20 \mathrm{mg}$ once daily from day 1 to day 5 , followed by $10 \mathrm{mg}$ once daily from day 6 to day 10).

Clinical examination, including pulse oximetric saturation $\left(\mathrm{SpO}_{2}\right)$ assessment, blood tests, and arterial blood gas analysis were performed according to routine clinical practice.

The study was conducted in accordance with the Declaration of Helsinki (revised version 2000) and was approved by the local Institutional Review Board.

\section{Oxygen delivery}

At the time of the enrollment in the study, all patients were provided with oxygen support, including nasal cannula (airflow between 2 and $6 \mathrm{~L} / \mathrm{min}$ ), Venturi mask (airflow between 8 and $10 \mathrm{~L} / \mathrm{min}$ ), non-rebreather mask (airflow $15 \mathrm{~L} / \mathrm{min}$ ), and continuous positive airway pressure (CPAP).

\section{Definitions}

Cardiovascular (CV) disease included a history of myocardial infarction or unstable angina. Cerebrovascular disease included a history of ischemic or hemorrhagic stroke or transient ischemic attack. Obesity was defined according to a body mass index $(\mathrm{BMI}) \geq 30 \mathrm{~kg} / \mathrm{m}^{2}$. Chronic kidney disease (CKD) was defined for an estimated glomerular filtration rate $<60 \mathrm{~mL} / \mathrm{min} / 1.73 \mathrm{~m}^{2}$, according to the Cockcroft-Gault equation [21]. Chronic liver disease was defined as the progressive deterioration of liver function for more than six months secondary to toxins, alcohol abuse, infection, autoimmune disease, genetic and metabolic disorders. Fever was defined for a body temperature $>37.5^{\circ} \mathrm{C}$. The composite outcome was defined by the occurrence of death or admission to the intensive care unit (ICU), whatever came first.

\section{Study endpoints}

The primary endpoint of the study was the assessment of the respiratory function-expressed as $\mathrm{PaO}_{2} / \mathrm{FiO}_{2}$-after 10 days of dexamethasone treatment. Secondary endpoints included (i) the evaluation of $\mathrm{SpO}_{2}$ throughout the treatment period, (ii) the occurrence of the composite outcome, and (iii) the assessment of factors predicting the composite outcome.

\section{Statistical analysis}

The distribution of continuous data was examined using the Shapiro-Wilk test. Non-normally distributed continuous variables are expressed as median and interquartile range [IQR], while normally distributed variables are presented as mean \pm standard deviation (SD). Data with a non-Gaussian 
distribution were analyzed using the Mann-Whitney $U$ test, while categorical variables were compared using a Chisquared test or Fisher's exact test, as appropriate. Variations of continuous variables between two time points were tested with Wilcoxon signed rank test, while the McNemar's test was used for categorical variables. Given the limited number of events of the composite outcome $(n=13)$, we used a backward stepwise regression analysis to determine independent predictors for the composite outcome. Risk ratio (RR) and the corresponding $95 \%$ confidence interval $(95 \% \mathrm{CI})$ are presented. For all statistical analyses, a two-sided $p$ value $<0.05$ was considered as statistically significant. Analyses were performed using IBM SPSS Statistics for Mac, version 26.0 (IBM CO., Armonk, NY, USA) and GraphPad Prism, version 8.2 for Windows (GraphPad Software, La Jolla, CA, USA, www.graphpad.com).

\section{Results}

\section{Characteristics of the cohort}

Ninety-eight consecutive patients were included in the present study, the majority being males $(n=61,62.2 \%)$ and with a mean age of 69 years (Table 1). A small number of patients $(5,5.9 \%)$ tested negative for SARS-CoV-2 but presented interstitial pneumonia on imaging that was highly suggestive for COVID-19. Before hospitalization, most common symptoms were fever $(n=93,94.9 \%)$ and dyspnea $(n=80,81.6 \%)$. Laboratory tests showed increased values of all acute-phase reactants, including CRP), ferritin, and fibrinogen (Table 1).

Hypertension was the most frequent comorbidity, followed by CV disease $(n=41,41.8 \%)$ and obesity $(n=36$, $36.7 \%)$.

At baseline (i.e., pre-high-dose dexamethasone treatment), all patients were on oxygen therapy. Most of them were on a non-rebreather (34.8\%) or a Venturi mask (30.8\%). Fifteen patients (16.5\%) were on CPAP. Details on oxygen delivery are summarized in Supplementary Fig. 1.

\section{Oxygen values during the study period}

After 10 days of high-dose dexamethasone treatment, a statistically significant improvement in $\mathrm{PaO}_{2} / \mathrm{FiO}_{2}(277.41$ [178.5-374.8] vs. 146.75 [93.62-231.16], $p<0.001), \mathrm{PaO}_{2}$ (88.15 [76.62-112.0] $\mathrm{mmHg}$ vs. 65.65 [57.07-81.22] $\mathrm{mmHg}, p<0.001$ ), and $\mathrm{SpO}_{2}(96$ [95-98]\% vs. 94 [90-96]\%, $p<0.001$ ) was found (Fig. 1 A-C and Supplementary Table 1). This held true also at day 3 and day 5 when compared with baseline (Fig. 1A-C).

A reduction in supplemental oxygen therapy, evaluated through $\mathrm{FiO}_{2}$ values, was recorded at the 10th day of
Table 1 Patients' characteristics at baseline (i.e., before high-dose dexamethasone treatment)

\begin{tabular}{|c|c|}
\hline & Overall cohort $(n=98)$ \\
\hline \multicolumn{2}{|l|}{ Anthropometric parameters } \\
\hline Males $n(\%)$ & $61(62.2 \%)$ \\
\hline Females $n(\%)$ & $37(36.7 \%)$ \\
\hline Age, years & $69 \pm 13$ \\
\hline Weight, kg & $75[65-84]$ \\
\hline Height, m & $1.69 \pm 0.09$ \\
\hline BMI, $\mathrm{kg} / \mathrm{m}^{2}$ & $25.4[22.9-29.2]$ \\
\hline \multicolumn{2}{|l|}{ Comorbidities } \\
\hline Hypertension, $n(\%)$ & $57(58.2 \%)$ \\
\hline Cardiovascular diseases, $n(\%)$ & $41(41.8 \%)$ \\
\hline Diabetes, $n(\%)$ & $20(20.4 \%)$ \\
\hline Obesity, $n(\%)$ & $36(36.7 \%)$ \\
\hline Cerebrovascular diseases, $n(\%)$ & $19(19.4 \%)$ \\
\hline COPD, $n(\%)$ & $11(11.2)$ \\
\hline Cancer, $n(\%)$ & $12(12.2 \%)$ \\
\hline Liver disease, $n(\%)$ & $3(3.1 \%)$ \\
\hline $\mathrm{CKD}, n(\%)$ & $8(8.2 \%)$ \\
\hline Autoimmune diseases, $n(\%)$ & $2(2.0 \%)$ \\
\hline \multicolumn{2}{|l|}{ Symptoms at onset } \\
\hline Cough, $n(\%)$ & $59(60.2 \%)$ \\
\hline Fever, $n(\%)$ & $93(94.9 \%)$ \\
\hline Dyspnea, $n(\%)$ & $80(81.6 \%)$ \\
\hline Gastrointestinal symptoms, $n(\%)$ & $13(13.3 \%)$ \\
\hline Days from symptom onset & 9 [7-12] \\
\hline \multicolumn{2}{|l|}{ Pre-steroid treatment } \\
\hline Antiviral drugs, $n(\%)$ & $44(44.9 \%)$ \\
\hline Hydroxychloroquine, $n(\%)$ & $90(91.8 \%)$ \\
\hline Azithromycin, $n(\%)$ & $22(22.4 \%)$ \\
\hline Levofloxacin, $n(\%)$ & $51(52.0 \%)$ \\
\hline Ceftriaxone, $n(\%)$ & $46(46.9 \%)$ \\
\hline LMWH, $n(\%)$ & $93(94.9 \%)$ \\
\hline Tocilizumab, $n(\%)$ & $5(5.1 \%)$ \\
\hline \multicolumn{2}{|l|}{ Laboratory tests } \\
\hline $\mathrm{WBC}\left(\times 10^{3} / \mathrm{mL}\right)$ & $7.21[5.9-9.4]$ \\
\hline $\mathrm{RBC}\left(\times 10^{6} / \mathrm{mL}\right)$ & $4.41 \pm 1.86$ \\
\hline Hemoglobin (g/dL) & $13.01 \pm 1.86$ \\
\hline PLT $\left(\times 10^{3} / \mathrm{mL}\right)$ & 208.5 [160.7-265.0] \\
\hline $\mathrm{CRP}(\mathrm{mg} / \mathrm{L})$ & 132.2 [82.3-186.5] \\
\hline Ferritin (ng/mL) & $1169.0[665.0-2,056.0]$ \\
\hline Fibrinogen (mg/dL) & $615.0[505.5-689.0]$ \\
\hline D-dimer $(\mu \mathrm{g} / \mathrm{L})$ & $1980 \pm 2919.3$ \\
\hline
\end{tabular}

$B M I$ body mass index; $C O P D$ chronic obstructive pulmonary disease; $C K D$ chronic kidney disease; $C R P$ C-reactive protein; $L M W H$ lowmolecular-weight heparin; PLT platelets; $R B C$ red blood cells; $W B C$ white blood cells

treatment compared with baseline ( 0.35 [0.26-0.50] vs. 0.50 [0.28-0.80], $p<0.001$ ) (Supplementary Fig. 2). A decrease in the number of patients using a non-rebreather mask was 
A

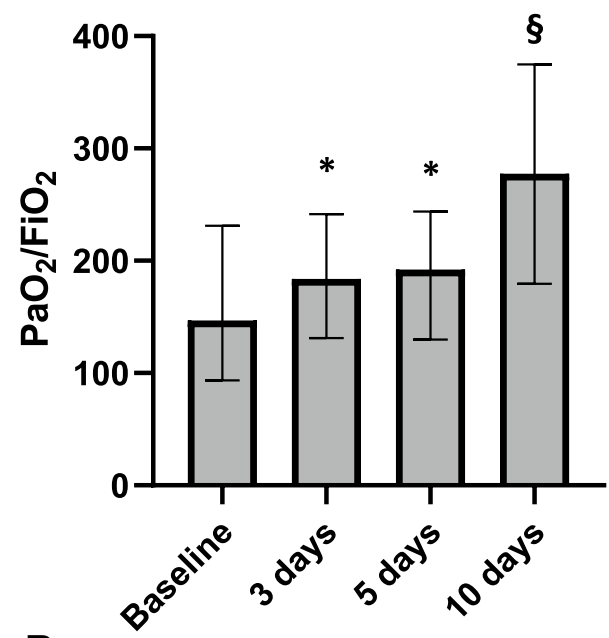

B

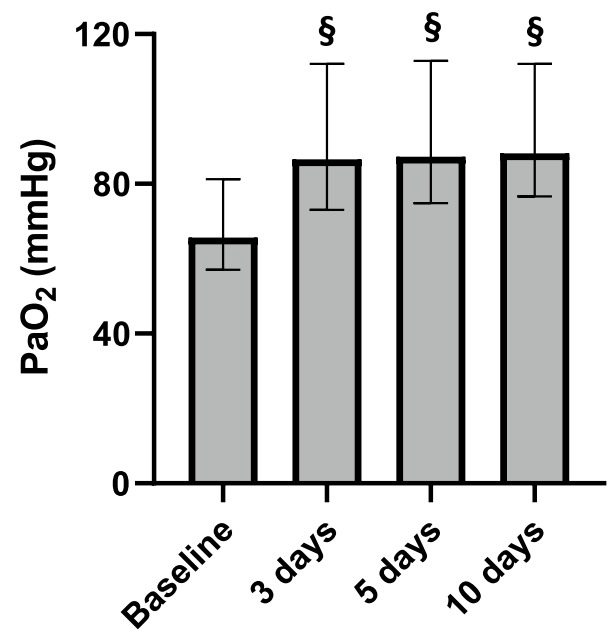

C

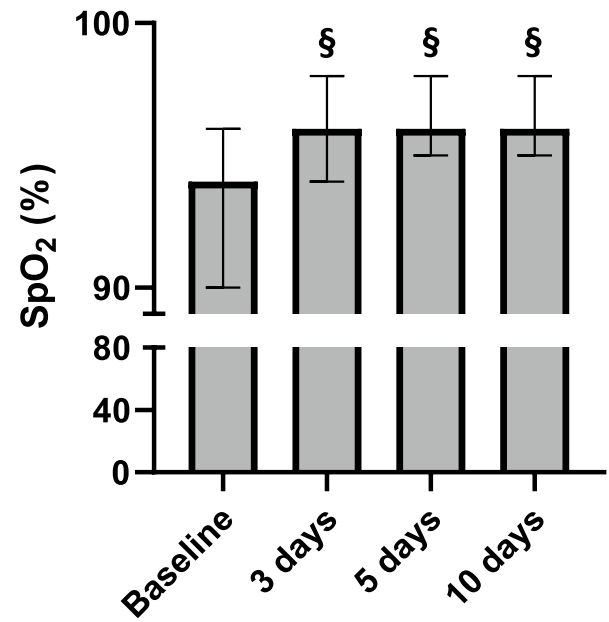

Fig. 1 Improvement of respiratory function over the treatment period. A progressive and statistically significant improvement in $\mathrm{PaO}_{2} / \mathrm{FiO}_{2}$ (panel A), $\mathrm{PaO}_{2}$ (panel $\mathrm{B}$ ), and $\mathrm{SpO}_{2}$ (panel C) was observed starting from day 3 of dexamethasone treatment. $\mathrm{PaO}_{2}$ arterial oxygen partial pressure, $\mathrm{PaO} / \mathrm{FiO} 2$ arterial oxygen partial pressure to fractional inspired oxygen ratio, $\mathrm{SpO} 2$ pulse oximetric saturation. ${ }^{*} p<0.05$ and ${ }^{\S} p<0.001$ vs. baseline for Wilcoxon signed rank test

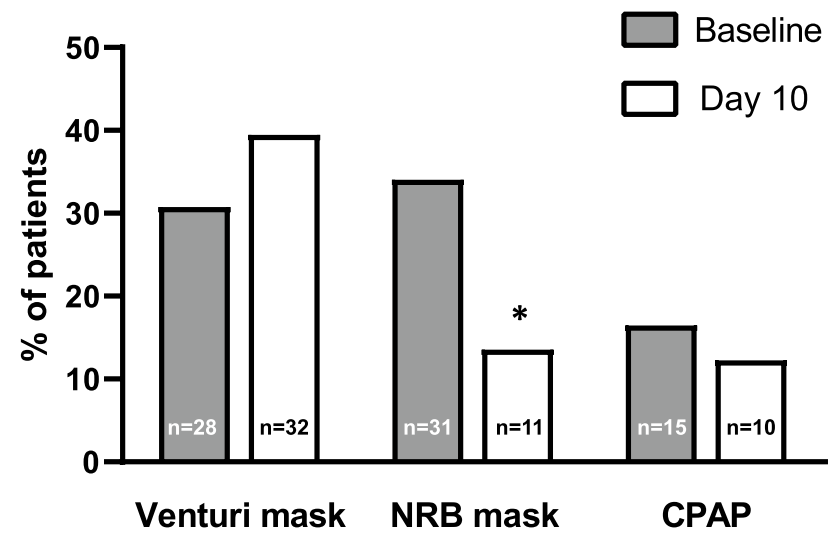

Fig. 2 Oxygen support throughout the study period. The number of patients using a non-rebreather mask significantly decreased from baseline to day $10(p=0.004)$. A non-statistically significant reduction in the use of CPAP was observed. As well, a non-statistically significant increase in the proportion of patients using a Venturi mask was recorded. CPAP continuous positive airway pressure. $* p<0.05$ vs. baseline for McNemar's test

found from baseline to day $10(34.1 \%, n=31$ vs. $13.6 \%$, $n=11, p=0.004)$, while a non-statistically significant reduction in the number of patients on CPAP was observed across the same time lapse (Fig. 2). A non-statistically significant increase in the proportion of patients on Venturi mask was observed from baseline to day 10 (Fig. 2).

\section{Clinical response during dexamethasone treatment}

After 10 days of high-dose dexamethasone, 9 out of 98 patients $(9.2 \%)$ died, whereas $4(4.1 \%)$ were admitted to the ICU for invasive mechanical ventilation.

A statistically significant reduction in the number of patients with fever $(94.9 \%$ vs. $6.1 \%, p<0.001)$, dyspnea (81.6\% vs. $20.4 \%, p<0.001)$, and cough $(60.2 \%$ vs. $21.4 \%$, $p<0.001)$ was recorded, while no change was observed in gastrointestinal symptoms (13.3 vs. $5.1 \%, p=0.077$ ) (Fig. 3). With regard to laboratory tests, CRP and ferritin significantly decreased after 10 days (132.25 [82.27-186.5] $\mathrm{mg} / \mathrm{L}$ vs. 7.3 [3.3-24.2] mg/L and 1169 [665-2056] ng/mL vs. 874.0 [569.5-1434] ng/mL, respectively; $p<0.001$ for both), while fibrinogen did not (615.0 [505.5-689.0] mg/ dL vs. 387.0 [282.0-535.0] mg/dL, $p=0.109$ ) (Fig. 4A-C).

Using a backward stepwise analysis (including age, sex, weight, baseline ferritin, baseline $\mathrm{PaO}_{2} / \mathrm{FiO}_{2}, \mathrm{CV}$ disease, hypertension, diabetes, cerebrovascular disease, chronic liver and kidney disease, obesity, COPD, and cancer), $\mathrm{CV}$ disease was found to increase the risk of occurrence of the composite outcome (RR 7.64, 95\% CI 1.24-47.06, $p=0.028$ ), while weight appeared to reduce this risk ( $\mathrm{RR}$ $0.90,95 \%$ CI $0.81-1.00, p=0.041)$. 


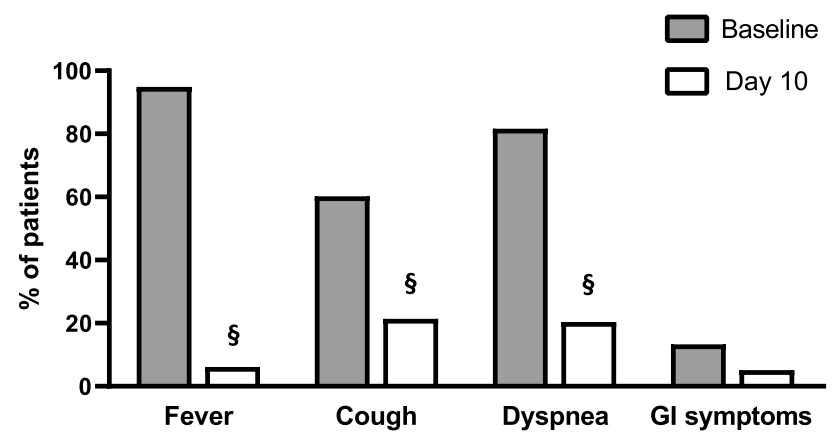

Fig. 3 Symptoms over treatment period. Across the 10-day treatment period, the majority of patients experienced an improvement in fever, cough, and dyspnea, while no difference was found for gastrointestinal symptoms. GI gastrointestinal. ${ }^{\S} p<0.001$ vs. baseline for $\mathrm{McNe}-$ mar's test

\section{Adverse events}

The number of adverse events (AEs) was low. The most frequent $\mathrm{AE}$ was delirium $(n=18,18 \%)$, followed by new-onset atrial fibrillation $(n=4,4 \%)$, hyperglycemia $(n=3,3 \%)$, and herpes zoster $(n=1,1 \%)$. No infections were recorded during the treatment period.

\section{Discussion}

In our retrospective, observational study involving nearly 100 consecutively hospitalized patients with ARDS secondary to SARS-CoV-2 pneumonia and treated with intravenous infusion of dexamethasone for 10 days, we found a significant improvement in the respiratory function, evaluated through $\mathrm{PaO}_{2} / \mathrm{FiO}_{2}$, as well as a rapid reduction of oxygen needs. The treatment had very few AEs, most of them represented by delirium, which is commonly experienced in patients treated with glucocorticoids [22].

A wealth of evidence points to the exaggerated host inflammatory response as the main cause for SARS-CoV2-related ARDS, similar to what happens in macrophage activation syndrome or chimeric antigen receptor-T-cellrelated cytokine release syndrome [9, 23]. Indeed, after the initial "viremic phase", in a subgroup of patients infiltrating monocytes, macrophages, neutrophils, lung epithelial and endothelial cells start producing large quantities of inflammatory cytokines-i.e., IL-6, TNF- $\alpha$, IL-18, GM-CSF, and interferon- $\gamma$ - that determine severe $\operatorname{ARDS}[6,8,10,11,24]$. This concept has promoted a large number of clinical trials testing immunomodulating agents, with controversial or neutral results $[8,25]$.

From in vitro and in vivo studies, glucocorticoids are well known to inhibit pro-inflammatory cytokines, such as IL-1 $\beta$, TNF- $\alpha$, and IL-6 [26]. Accordingly, high-dose

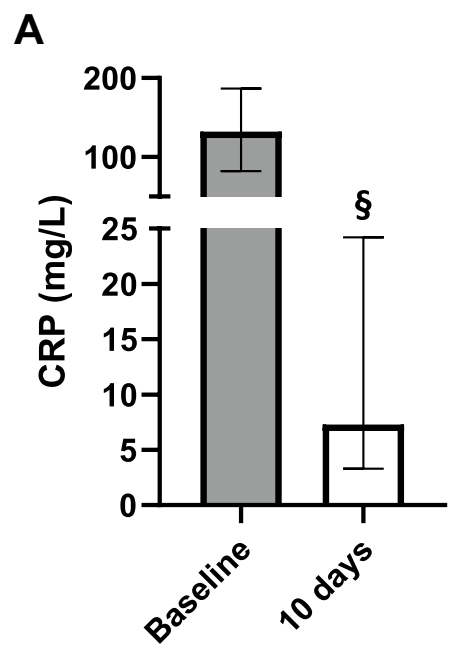

B
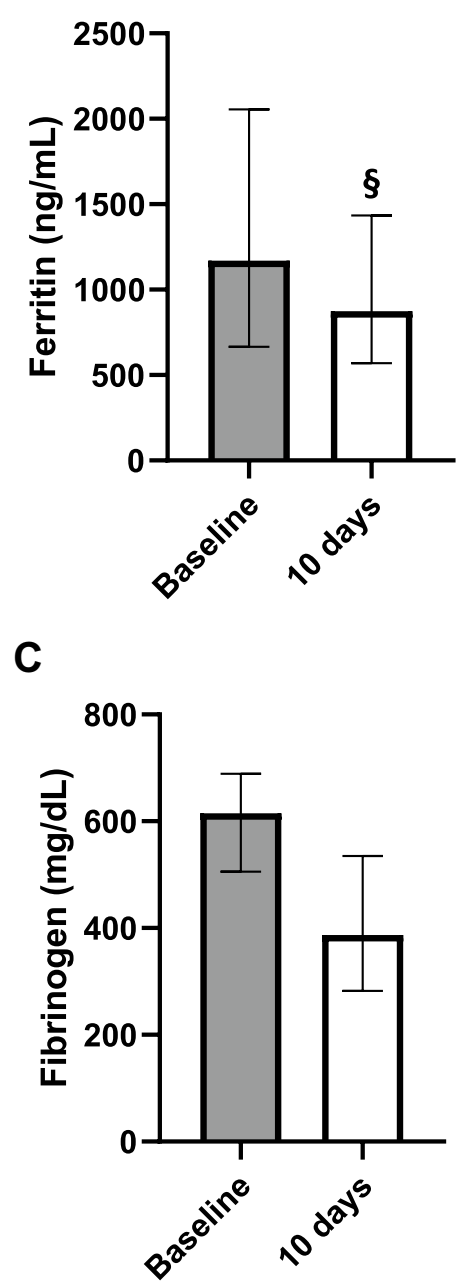

Fig. 4 Inflammatory biomarkers over treatment period. Following the 10-day dexamethasone treatment, a striking improvement in CRP and ferritin levels was observed (panels A-B), while only a trend for a decrease in fibrinogen was recorded (panel C). CRP C-reactive protein, $G I$ gastrointestinal, ${ }^{\S} p<0.001$ vs. baseline for Wilcoxon signed rank test 
glucocorticoids could be used in patients who develop a hyperinflammatory response (defined by the concomitant presence of ARDS, worsening of the respiratory function, and increasing value of CRP at least 7 days after symptoms onset) to prevent ARDS or its progression. Previous studies in patients with SARS and Middle East respiratory syndrome (MERS) treated with glucocorticoids were generally controversial. Most of them described a potential harm rather than a benefit due to a delay in viral clearance, with only few of them showing beneficial results [27-29].

Villar et al. demonstrated that high-dose dexamethasone shortened the duration of mechanical ventilation and reduced overall mortality in patients with moderate-to-severe ARDS [20]. The RECOVERY trial has shown that low-dose dexamethasone for 10 days provided a $20 \%$ reduction in 28-day mortality in COVID-19-related ARDS patients, especially among those on invasive mechanical ventilation and on oxygen support [19]. Tomazini et al. investigated the efficacy of intravenous high-dose dexamethasone $(20 \mathrm{mg}$ daily for 5 days, followed by $10 \mathrm{mg}$ daily for other 5 days) plus standard care vs. standard care alone in patients with COVID19 and moderate-to-severe ARDS. They concluded that the use of dexamethasone plus standard care increased the number of ventilator-free days compared with standard care alone [30]. A prospective meta-analysis evaluating systemic administration of glucocorticoids compared with usual care or placebo in critically ill patients with COVID-19 has shown to lower 28-day all-cause mortality as well [31]. Our data with high-dose dexamethasone confirmed the abovementioned findings with a rapid improvement in terms of respiratory function starting from day 3 , as highlighted by the increase in the $\mathrm{PaO}_{2} / \mathrm{FiO}_{2}$ and $\mathrm{SpO}_{2}$. After 10 days of treatment, most of the patients had their symptoms (fever, dyspnea, and cough) improved along with a low rate of AEs, in particular no infection was recorded.

Finally, when considering patients' comorbidities, we found that a history of $\mathrm{CV}$ disease was the only factor negatively affecting patients' outcome. This is not unexpected, as $\mathrm{CV}$ disease was recognized as a negative prognostic factor in other studies [5, 32, 33].

In spite of these positive results, recently some papers came out questioning the positive effects of high-dose glucocorticoids, either dexamethasone or methylprednisolone [34-36]. However, other studies supported the beneficial effects of an immediate blunting of hyperinflammation using high-dose glucocorticoids in terms of increased survival [37-39].

Our study, however, is not without limitations. The retrospective nature, the limited number of patients, and the absence of a control group cannot allow to demonstrate a definitive efficacy of glucocorticoid treatment. Given the challenging period during which the study was conducted, some data were incomplete or missing.
In conclusion, this retrospective observational study in hospitalized patients treated with high-dose dexamethasone during the hyperinflammatory phase of COVID-19 showed a rapid and significant improvement in clinical and laboratory parameters along with a low rate of AEs. Randomized clinical trials are eagerly needed to confirm our positive, preliminary data with high-dose dexamethasone in COVID-19 patients. Indeed, REMED is a prospective, phase II, openlabel, randomized controlled trial comparing the efficacy of dexamethasone $20 \mathrm{mg}$ vs. $6 \mathrm{mg}$ daily (NCT04663555, EudraCT No.:2020-005,887-70) [40].

Supplementary Information The online version contains supplementary material available at https://doi.org/10.1007/s11739-021-02800-1.

Authors' contribution ABa, FT, BP, AA, RC, SF, AMM, and DDG collected the data and designed the database. AV, Aba, and ABo performed the statistical analyses and drafted the first version of the manuscript. FT, NM, OP, AMM, DDG, and FD critically revised the manuscript. AV and $\mathrm{ABa}$ equally contributed as first authors to this work. All authors approved the final version of the manuscript.

\section{Declarations}

Conflict of interest Dr. Bonaventura and Dr. Vecchié received a travel grant from Kiniksa Pharmaceuticals Ltd. to attend the 2019 AHA Scientific Sessions and receive honoraria from Effetti s.r.l. (Milan, Italy) to collaborate on the medical website www.inflammology.org. The remaining authors have nothing to disclose related to this study.

Statements on human and animal rights The study was conducted in accordance with the Declaration of Helsinki (revised version 2000) and was approved by the local Institutional Review Board.

Informed consent Patient consent was collected before study inclusion.

\section{References}

1. Zhu N, Zhang D, Wang W, Li X, Yang B, Song J et al (2020) A novel coronavirus from patients with pneumonia in China, 2019. N Engl J Med 382:727-733

2. Huang C, Wang Y, Li X, Ren L, Zhao J, Hu Y et al (2020) Clinical features of patients infected with 2019 novel coronavirus in Wuhan. China Lancet 395:497-506

3. Zheng Z, Peng F, Xu B, Zhao J, Liu H, Peng J et al (2020) Risk factors of critical \& mortal COVID-19 cases: a systematic literature review and meta-analysis. J Infect 81:e16-e25

4. Ruan Q, Yang K, Wang W, Jiang L, Song J (2020) Clinical predictors of mortality due to COVID-19 based on an analysis of data of 150 patients from Wuhan China. Intensive Care Med 46:846-848

5. Zhou F, Yu T, Du R, Fan G, Liu Y, Liu Z et al (2020) Clinical course and risk factors for mortality of adult inpatients with COVID-19 in Wuhan, China: a retrospective cohort study. Lancet 395:1054-1062

6. McGonagle D, Sharif K, O'Regan A, Bridgewood C (2020) The role of cytokines including interleukin- 6 in COVID-19 induced pneumonia and macrophage activation syndrome-like disease. Autoimmun Rev 19:102537 
7. Sainz B Jr, Mossel EC, Peters CJ, Garry RF (2004) Interferon-beta and interferon-gamma synergistically inhibit the replication of severe acute respiratory syndrome-associated coronavirus (SARSCoV). Virology 329:11-17

8. Potere N, Batticciotto A, Vecchie A, Porreca E, Cappelli A, Abbate A et al (2021) The role of IL-6 and IL-6 blockade in COVID-19. Expert Rev Clin Immunol 25:1-17

9. Mehta P, McAuley DF, Brown M, Sanchez E, Tattersall RS, Manson JJ et al (2020) COVID-19: consider cytokine storm syndromes and immunosuppression. Lancet 395:1033-1034

10. Bonaventura A, Vecchie A, Wang TS, Lee E, Cremer PC, Carey B et al (2020) Targeting GM-CSF in COVID-19 pneumonia: rationale and strategies. Front Immunol 11:1625

11. Vecchie A, Bonaventura A, Toldo S, Dagna L, Dinarello CA, Abbate A (2020) IL-18 and infections: is there a role for targeted therapies? J Cell Physiol 236(3):1638-1657

12. Bonaventura A, Vecchie A, Dagna L, Martinod K, Dixon DL, Van Tassell BW et al (2021) Endothelial dysfunction and immunothrombosis as key pathogenic mechanisms in COVID-19. Nat Rev Immunol 21:319-329

13. Beigel JH, Tomashek KM, Dodd LE, Mehta AK, Zingman BS, Kalil AC et al (2020) Remdesivir for the treatment of Covid-19 final report. N Engl J Med 383(19):1813-1826

14. Cavalli G, De Luca G, Campochiaro C, Della-Torre E, Ripa M, Canetti D et al (2020) Interleukin-1 blockade with high-dose anakinra in patients with COVID-19, acute respiratory distress syndrome, and hyperinflammation: a retrospective cohort study. Lancet Rheumatol 2:e325-e331

15. Geleris J, Sun Y, Platt J, Zucker J, Baldwin M, Hripcsak G et al (2020) Observational study of hydroxychloroquine in hospitalized patients with Covid-19. N Engl J Med 382:2411-2418

16. Hermine O, Mariette X, Tharaux PL, Resche-Rigon M, Porcher R, Ravaud P et al (2020) Effect of tocilizumab vs. usual care in adults hospitalized with COVID-19 and moderate or severe pneumonia: a randomized clinical trial. JAMA Intern Med 181(1):32-40

17. Stone JH, Frigault MJ, Serling-Boyd NJ, Fernandes AD, Harvey L, Foulkes AS et al (2020) Efficacy of tocilizumab in patients hospitalized with Covid-19. N Engl J Med 383(24):2333-2344

18. Salvarani C, Dolci G, Massari M, Merlo DF, Cavuto S, Savoldi L et al (2020) Effect of tocilizumab vs. standard care on clinical worsening in patients hospitalized With COVID-19 pneumonia: a randomized clinical trial. JAMA Intern Med 181(1):24-31

19. RECOVERY Collaborative Group; Horby P, Lim WS, Emberson JR, Mafham M, Bell JL et al (2021) Dexamethasone in Hospitalized Patients with Covid-19. N Engl J Med 384(8):693-704

20. Villar J, Ferrando C, Martinez D, Ambros A, Munoz T, Soler JA et al (2020) Dexamethasone treatment for the acute respiratory distress syndrome: a multicentre, randomised controlled trial. Lancet Respir Med 8:267-276

21. Cockcroft DW, Gault MH (1976) Prediction of creatinine clearance from serum creatinine. Nephron 16:31-41

22. Cole JL (2020) Steroid-induced sleep disturbance and delirium: a focused review for critically Ill patients. Fed Pract 37:260-267

23. Brudno JN, Kochenderfer JN (2016) Toxicities of chimeric antigen receptor $\mathrm{T}$ cells: recognition and management. Blood 127:3321-3330

24. Siddiqi HK, Mehra MR (2020) COVID-19 illness in native and immunosuppressed states: a clinical-therapeutic staging proposal. J Heart Lung Trans 39:405-407

25. Cavalli G, Farina N, Campochiaro C, De Luca G, Della-Torre E, Tomelleri A et al (2020) Repurposing of biologic and targeted synthetic anti-rheumatic drugs in COVID-19 and hyper-inflammation: a comprehensive review of available and emerging evidence at the peak of the pandemic. Front Pharmacol 11:598308
26. Brattsand R, Linden M (1996) Cytokine modulation by glucocorticoids: mechanisms and actions in cellular studies. Aliment Pharmacol Ther 10(Suppl 2):81-90

27. Arabi YM, Mandourah Y, Al-Hameed F, Sindi AA, Almekhlafi GA, Hussein MA et al (2018) Corticosteroid therapy for critically ill patients with middle east respiratory syndrome. Am J Respir Crit Care Med 197:757-767

28. Perlman S, Dandekar AA (2005) Immunopathogenesis of coronavirus infections: implications for SARS. Nat Rev Immunol 5:917-927

29. Stockman LJ, Bellamy R, Garner P (2006) SARS: systematic review of treatment effects. PLoS Med 3:e343

30. Tomazini BM, Maia IS, Cavalcanti AB, Berwanger O, Rosa RG, Veiga VC et al (2020) Effect of dexamethasone on days alive and ventilator-free in patients with moderate or severe acute respiratory distress syndrome and COVID-19: the CoDEX randomized clinical trial. JAMA 324:1307-1316

31. Group WHOREAfC-TW, Sterne JAC, Murthy S, Diaz JV, Slutsky AS, Villar J et al (2020) Association between administration of systemic corticosteroids and mortality among critically Ill patients with COVID-19 a meta-analysis. JAMA 324:1330-1341

32. Richardson S, Hirsch JS, Narasimhan M, Crawford JM, McGinn T, Davidson KW et al (2020) Presenting characteristics, comorbidities, and outcomes among 5700 patients hospitalized with COVID-19 in the New York City Area. JAMA 323:2052-2059

33. Pinney SP, Giustino G, Halperin JL, Mechanick JI, Neibart E, Olin JW et al (2020) Coronavirus historical perspective, disease mechanisms, and clinical outcomes: JACC focus seminar. J Am Coll Cardiol 76:1999-2010

34. Jamaati H, Hashemian SM, Farzanegan B, Malekmohammad M, Tabarsi P, Marjani M et al (2021) No clinical benefit of high dose corticosteroid administration in patients with COVID-19: a preliminary report of a randomized clinical trial. Eur J Pharmacol $897: 173947$

35. Dolci G, Cassone G, Venturelli F, Besutti G, Revelli M, Corsini $R$ et al (2021) High-dose glucocorticoids pulse-therapy for betacoronaviridae pneumonia: a systematic literature review and caseseries of Coronavirus disease-2019. Clin Exp Rheumatol. 2021 Feb 26. Online ahead of print.

36. Piccica M, Lagi F, Trotta M, Spinicci M, Zammarchi L, Bartoloni A et al. High-dose steroids for the treatment of severe COVID-19. Intern Emerg Med 2021;1-5. https://doi.org/10.1007/ s11739-021-02707-x

37. Papamanoli A, Yoo J, Grewal P, Predun W, Hotelling J, Jacob $R$ et al (2021) High-dose methylprednisolone in nonintubated patients with severe COVID-19 pneumonia. Eur J Clin Invest 51:e13458

38. Lopez Zuniga MA, Moreno-Moral A, Ocana-Granados A, PadillaMoreno FA, Castillo-Fernandez AM, Guillamon-Fernandez D et al (2021) High-dose corticosteroid pulse therapy increases the survival rate in COVID-19 patients at risk of hyper-inflammatory response. PLoS ONE 16:e0243964

39. Pinzon MA, Ortiz S, Holguin H, Betancur JF, Cardona Arango $\mathrm{D}$, Laniado $\mathrm{H}$ et al (2021) Dexamethasone vs methylprednisolone high dose for Covid-19 pneumonia. PLoS ONE 16:e0252057

40. Malaska J, Stasek J, Duska F, Balik M, Maca J, Hruda J et al (2021) Effect of dexamethasone in patients with ARDS and COVID-19 - prospective, multi-centre, open-label, parallel-group, randomised controlled trial (REMED trial): a structured summary of a study protocol for a randomised controlled trial. Trials 22:172

Publisher's Note Springer Nature remains neutral with regard to jurisdictional claims in published maps and institutional affiliations. 